\title{
The Damage of Fly Ash -Slag Concrete under Sustained Loading in Marine Environments
}

\author{
$\mathrm{J} \mathrm{Gong}^{1}$, J Cao ${ }^{2}$ and $\mathrm{Y} \mathrm{F} \mathrm{Wang}{ }^{1}$ \\ ${ }^{1}$ School of Civil Engineering, Beijing Jiaotong University, Shangyuancun 3, Haidian District, Beijing 100044, PR China \\ ${ }^{2}$ School of Civil and Architectural Engineering, Nanchang Institute of Technology, Nanchang 330099, PR China.
}

\begin{abstract}
The durability damage of concrete structures in the actual engineering environment is often the result of the interaction of the load and the environment, climate and other multiple factors. In this paper, the test researches were carried out on the concrete mass and dynamic elastic modulus under the effects of sustained loading, sulfate attack and dry-wet circulation, and the test phenomenon and results were discussed and analyzed. Then this paper proposed the durability damage model of the concrete under the effects of sustained loading, sulfate attack and dry-wet circulation considering the compressive stress level, the sulfate solution concentration and the age of corrosion as test factors, and the rationality of the model was discussed.
\end{abstract}

\section{Introduction}

Neville [1] considered that it needs to recognize the importance of the interaction of multiple factors in the concrete durability theoretical research and practical engineering application. There are mainly two methods for the damage analysis of concrete structures under the coupled actions of multi-factors.

One method is that the damage models were established considering chemical ion corrosion, and the required parameters were determined through the analysis of test results. Tixier et al.[2,3] established the model to calculate the expansion of concrete which was under sulfate attack applying the physical and chemical mechanics. Saetta et al.[4-6] firstly calculated the mechanical damage and chemical damage separately and then coupled them, established the chemical mechanical model to simulate the sulfate salt corrosion of cement-based materials. Kuhl et al.[7,8] considered the precipitation of calcium in the concrete as chemical damage variable and combined with the concrete mechanical damage, and then established the chemical mechanical damage model to calculate the deterioration of mechanical properties.But a large number of unknown parameters needed to be identified in these models, and these key material parameters were determined empirically in the past.

Now the mathematical statistical method about the evolution of concrete durability damage based on the test results is widely applied.Schneider and Chen [9] conducted the compressive strength tests of the concrete members in different bending stress levels which were in the ammonium sulfate and ammonium nitrate solution with different solubility, through the regression analysis of the test data, they supposed the model of concrete time varying compressive strength considering the load and sulfate attacks. Maes et al.[10] conducted theoretical researches on the fatigue properties of the prestressed bridge structures which are under stress corrosion, and provided the model of cracking leading from stress corrosion. Xi et al.[11] studied the degeneration of concrete damage and durability caused by the diffusion process of the chemical ions, and proposed the united differential equation to solve the interaction problem .

This paper conducted experimental study on the concrete damage under different experimental conditions, providing the basis for proposing a concrete damage calculation model under the effects of sustained loading, sulfate attack and dry-wet circulation.

\section{Experimental program}

\subsection{Material properties}

A Portland cement with a specific density of $3.1 \mathrm{~g} / \mathrm{cm}^{3}$ was used.The coarse aggregates were natural crushed limestone, with size of $5-25 \mathrm{~mm}$. The used FA is classified as low calcium Class II. The design of mixture for the concrete specimen is shown in Table 1.

\subsection{Experimental parameters and test apparatus}

The test factors considered in this study include load stress level $(0,15 \%$ and 30\%), sulfate solution concentration $(1 \%, \quad 5 \%$ and $10 \%)$, immersion ways:long-term immersion(LM) and wet-dry cycle(DW).A new test apparatus was developed based on the guidelines provided by GB/T 50082-2009 [12], which is shown in figure1. 
Table 1. Design of the concrete specimen mixtures

\begin{tabular}{ccccccc}
\hline $\begin{array}{l}\text { Cement } \\
\left(\mathrm{kg} / \mathrm{m}^{3}\right)\end{array}$ & $\begin{array}{l}\text { Sand } \\
\left(\mathrm{kg} / \mathrm{m}^{3}\right)\end{array}$ & $\begin{array}{c}\text { Aggregate } \\
\left(\mathrm{kg} / \mathrm{m}^{3}\right)\end{array}$ & $\begin{array}{c}\text { Water } \\
\left(\mathrm{kg} / \mathrm{m}^{3}\right)\end{array}$ & $\begin{array}{c}\text { Fly ash } \\
\left(\mathrm{kg} / \mathrm{m}^{3}\right)\end{array}$ & $\begin{array}{c}\text { Slag } \\
\left(\mathrm{kg} / \mathrm{m}^{3}\right)\end{array}$ & $\begin{array}{c}\text { Water reducer } \\
\left(\mathrm{kg} / \mathrm{m}^{3}\right)\end{array}$ \\
\hline 296 & 729 & 1050 & 172 & 81 & 63 & 8.80 \\
\hline
\end{tabular}

The test factors considered in this study include load stress level $(0,15 \%$ and $30 \%)$, sulfate solution concentration(1\%, 5\% and 10\%), immersion ways:long-term immersion(LM) and wet-dry cycle(DW).A new test apparatus was developed based on the guidelines provided by GB/T 50082-2009 [12], which is shown in figure1.
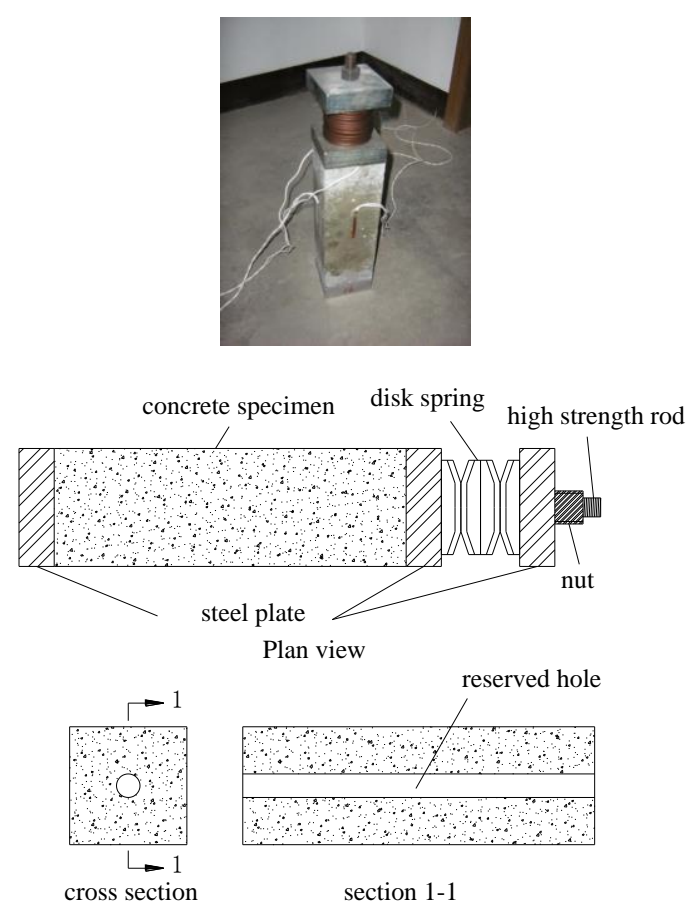

Figure 1. Loading equipment

\section{Analysis of test results}

\subsection{Mass}

The mass changes of the concrete which is in the long-term sulfate corrosion environment are shown in figure 2.

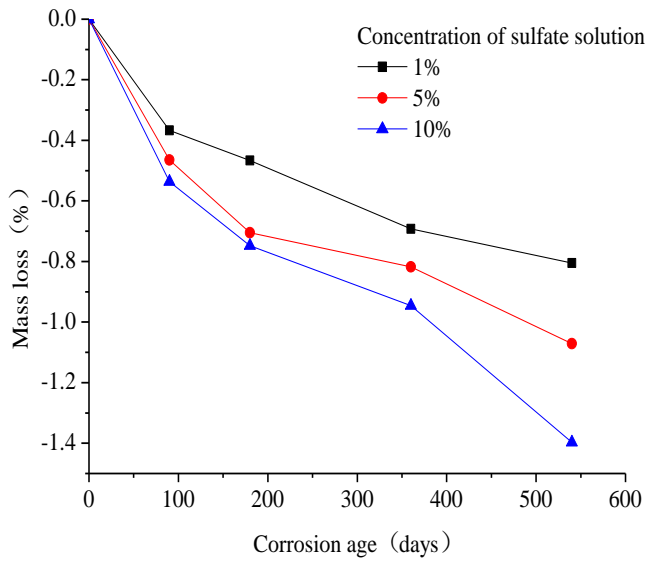

(a)

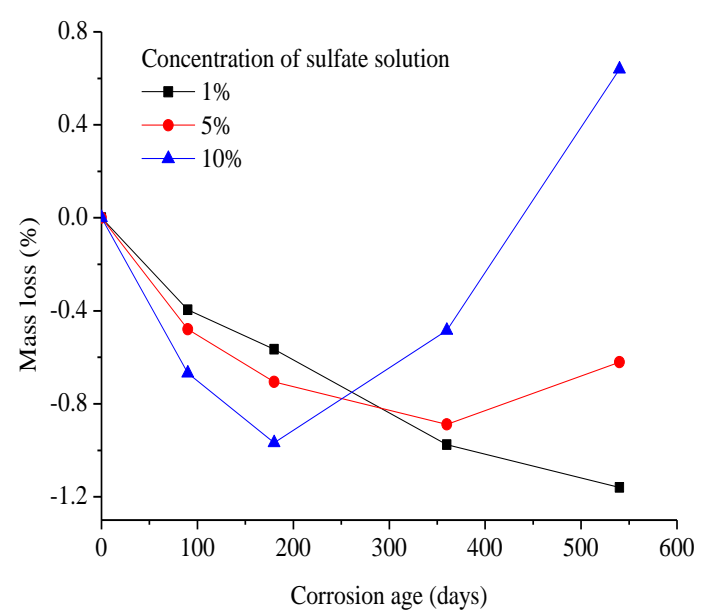

(b)

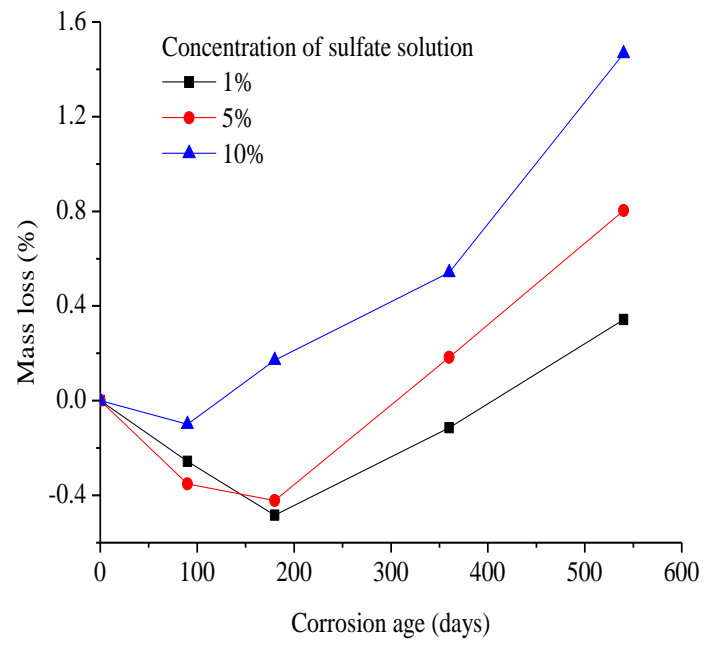

(c)

Figure 2. Mass change of concrete under long-term immersion of sulfate attack (a)the stress level is 0 (b) the stress level is $15 \%$ (c) the stress level is $30 \%$

From figure 2, when the stress level is 0, mass loss rates of the concrete in solution with different concentrations are all negative. When the stress level is $15 \%$, masses of concrete in solution with different concentrations have different changes with the corrosion age's increasing. For the solution with concentration of $1 \%$, mass increases along with the corrosion age's development. For the concentration of 5\%, concrete's mass first increases and then decreases. When the stress level is $30 \%$, masses of concrete in solution with different concentrations all first increase and then decrease with corrosion age's development.

The mass changes of the concrete which is in the wet and dry sulfate corrosion environment are shown in figure 3. 


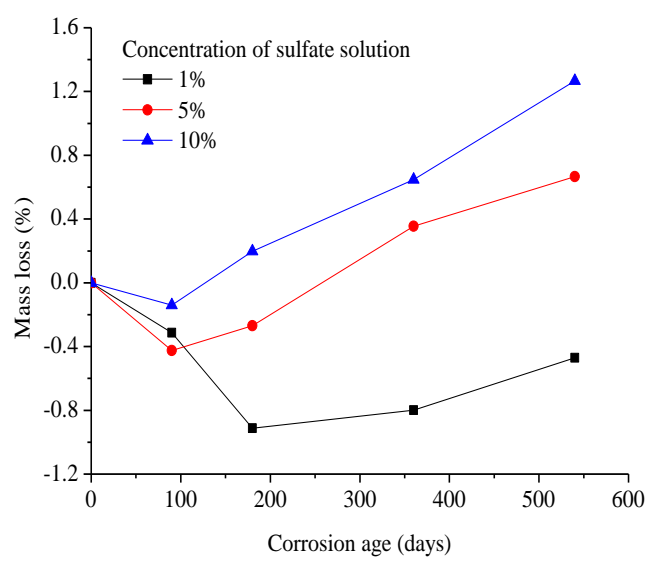

(a)

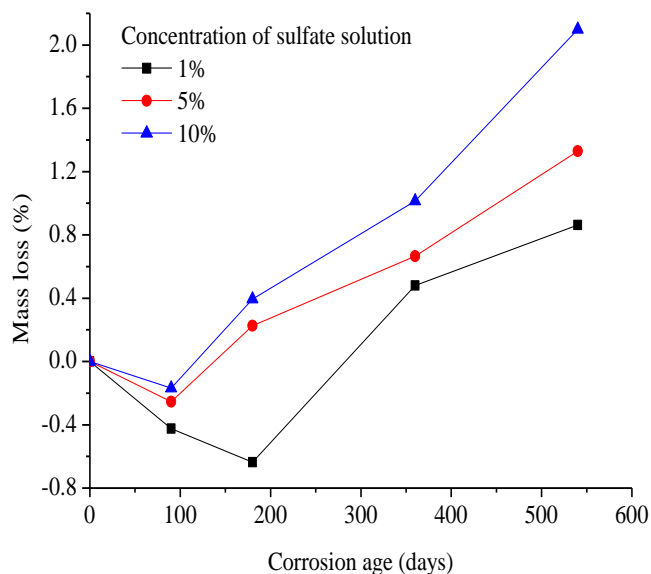

(b)

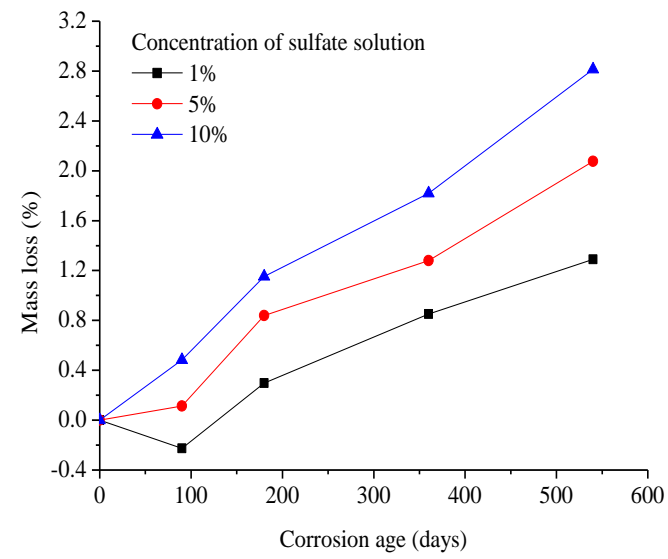

(c)

Figure 3. Mass change of concrete under dry-wet cycle and sulfate attack effects (a)the stress level is $0(\mathrm{~b})$ the stress level is $15 \%$ (c) the stress level is $30 \%$

From figure 3 , when the stress level is $0 \%$, masses of concrete in solution with different concentrations all first increase and then decrease with corrosion age's development. When the stress level is $15 \%$, masses of concrete in solution with different concentrations all first increase and then decrease with corrosion age's developing, it is similar to the trend without load. When the stress level is $30 \%$, mass of concrete in solution with different concentration decreases along with the corrosion age's developing, and the loss rate is proportional to the concentration value. For the specimens DW-S30-C5-D540 and DW-S30-C10-D540, the first two layers of concrete both peeled off, their mass loss are more serious.

\subsection{Dynamic elastic modulus}

The changing curves of relative dynamic elastic modulus of concrete within different stress level, different dipping and different concentrations of solution with the corrosion age's developing are shown in figure 4 and figure 5 .

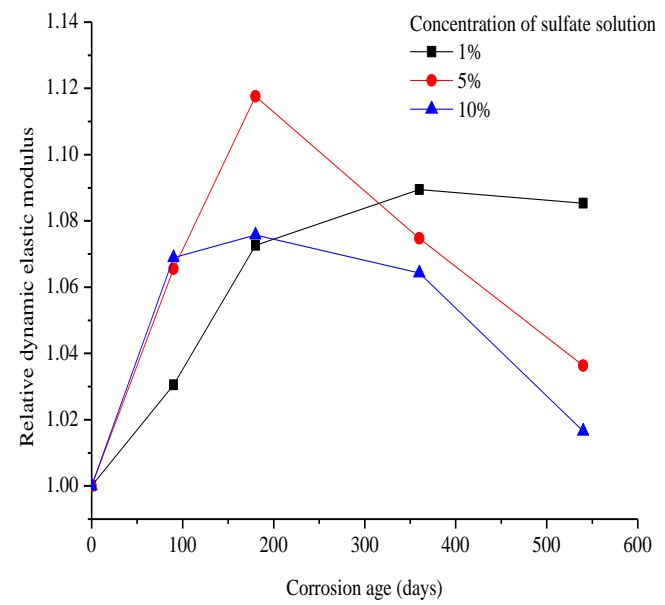

(a)

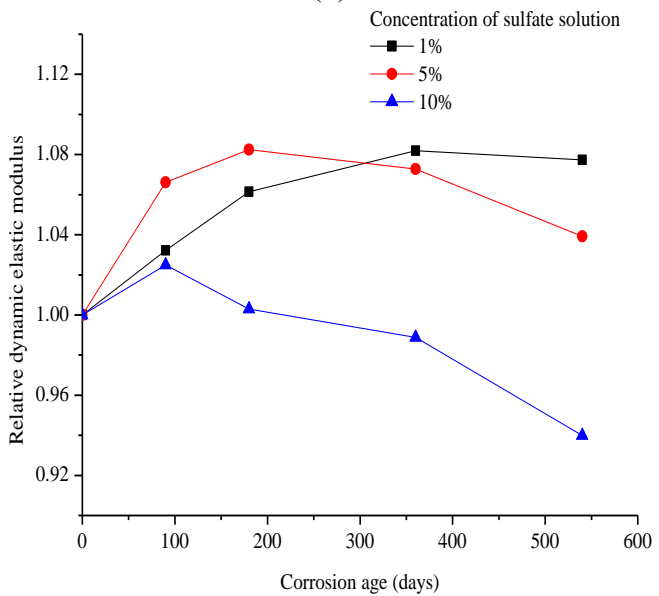

(b)

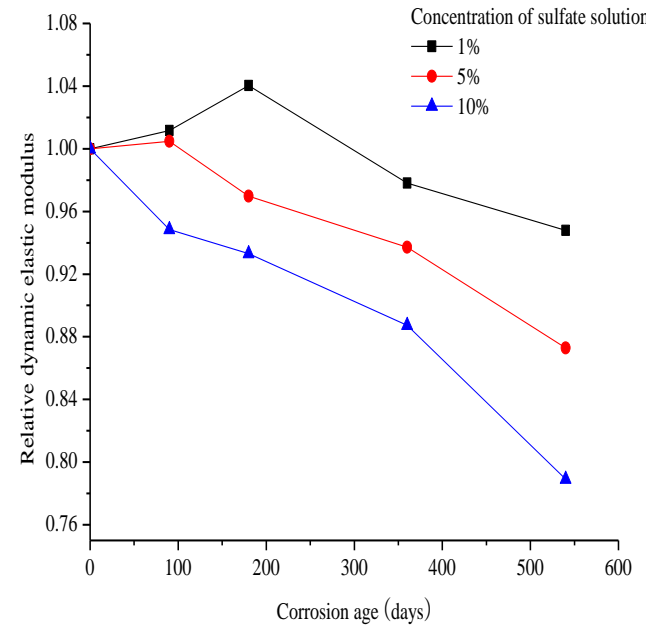

(c)

Figure 4. Relative dynamic elastic modulus long-term immersion of sulfate attack (a)the stress level is $0(\mathrm{~b})$ the stress level is $15 \%(\mathrm{c})$ the stress level is $30 \%($ Unit:104MPa) 
As shown in figure 4, in the long-term immersion environment, the relative dynamic elastic modulus of concrete in the sulfate solution with concentration of $1 \%$ increases with the corrosion age's developing when the stress level is 0 and $15 \%$. For the concrete in solution with concentration of $5 \%$ and $10 \%$, their relative dynamic elastic modulus first increase and then decrease with the corrosion age's increasing when the stress level is 0 and $15 \%$.

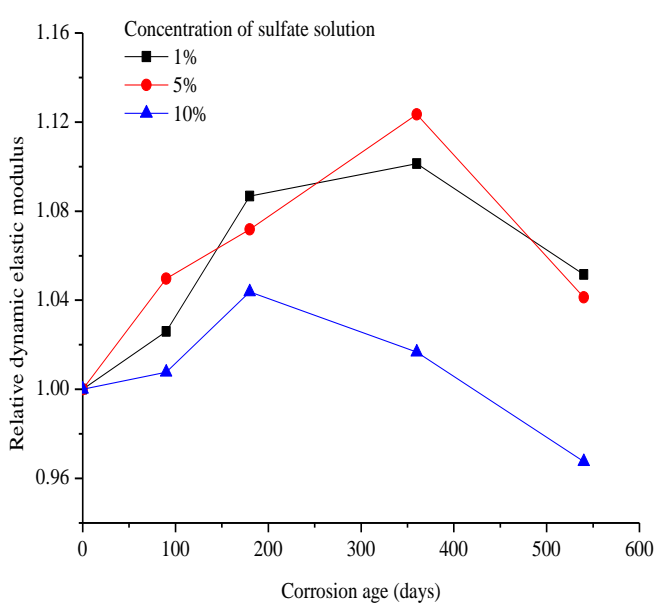

(a)

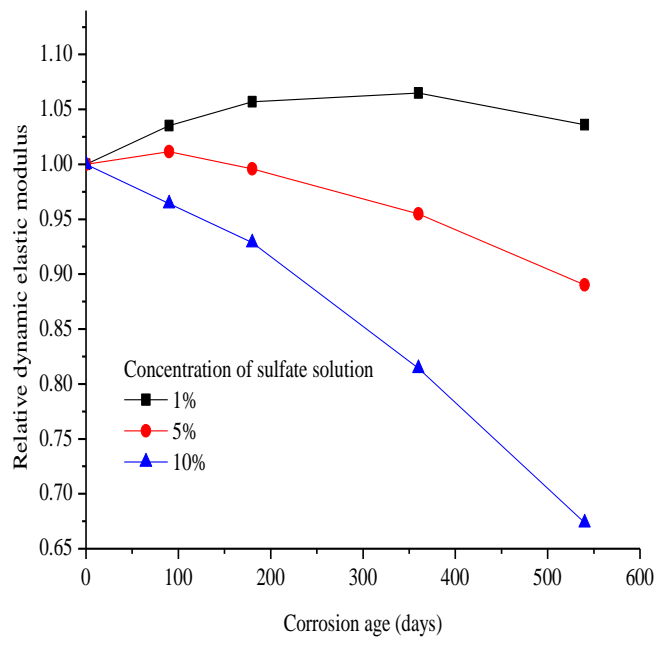

(b)

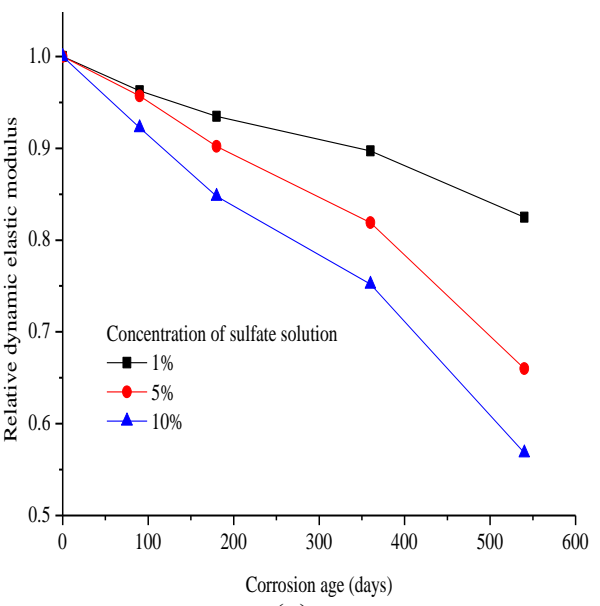

(c)

Figure 5. Relative dynamic elastic modulus under dry-wet cycle and sulfate attack effects (a)the stress level is $0(\mathrm{~b})$ the stress level is $15 \%$ (c) the stress level is $30 \%$ (Unit:104MPa)

From the figure 5 , when the stress level is 0 , relative dynamic elastic modulus of the concrete in sulfate solution with various concentrations all first increase and then decrease with the corrosion age's developing. When the stress level is $15 \%$, relative dynamic elastic modulus of concrete in the $1 \%$ and $5 \%$ concentrations of sulfate solution first increase and then decrease with the corrosion age's developing. For the situation that stress level is $30 \%$, relative dynamic elastic modulus of the concrete in various concentrations of sulfate solution all decrease with the corrosion age's developing.

\section{Damage model of concrete}

This paper regards the dynamic elastic modulus as the evaluation indicator of the durability damage of concrete ; the prediction model of the evolution with the corrosion age of dynamic elastic modulus of concrete under the situation of different stress level, different immersion way and different concentrations of sulfate solution is presented. Specifically as shown in equation (1):

$D=a+b \cdot t+c \cdot t^{2}$

Table 2. Regression coefficients of formula (1)

\begin{tabular}{|c|c|c|c|c|c|c|}
\hline $\begin{array}{l}\text { Immersion } \\
\text { way }\end{array}$ & Stress level & concentration & $\mathrm{a}$ & $\mathrm{b}$ & $\mathrm{c}$ & $\mathrm{R} 2$ \\
\hline \multirow{8}{*}{$\begin{array}{l}\text { Long-term } \\
\text { immersion }\end{array}$} & \multirow{3}{*}{0} & $1 \%$ & $1.220 \mathrm{E}-03$ & $-4.719 \mathrm{E}-04$ & $5.808 \mathrm{E}-07$ & 0.981 \\
\hline & & $5 \%$ & $-9.969 \mathrm{E}-03$ & $-6.687 \mathrm{E}-04$ & $1.211 \mathrm{E}-06$ & 0.822 \\
\hline & & $10 \%$ & $-1.112 \mathrm{E}-02$ & $-5.346 \mathrm{E}-04$ & $9.871 \mathrm{E}-07$ & 0.876 \\
\hline & \multirow{3}{*}{$15 \%$} & $1 \%$ & $-1.785 \mathrm{E}-04$ & $-4.155 \mathrm{E}-04$ & $5.071 \mathrm{E}-07$ & 0.997 \\
\hline & & $5 \%$ & $-1.042 \mathrm{E}-02$ & $-5.423 \mathrm{E}-04$ & $9.230 \mathrm{E}-07$ & 0.879 \\
\hline & & $10 \%$ & $-5.544 \mathrm{E}-03$ & $-1.072 \mathrm{E}-04$ & $4.255 \mathrm{E}-07$ & 0.932 \\
\hline & \multirow{2}{*}{$30 \%$} & $1 \%$ & $-4.679 \mathrm{E}-03$ & $-1.728 \mathrm{E}-04$ & $5.359 \mathrm{E}-07$ & 0.808 \\
\hline & & $5 \%$ & $-3.967 \mathrm{E}-03$ & $8.925 \mathrm{E}-05$ & $2.835 \mathrm{E}-07$ & 0.981 \\
\hline
\end{tabular}




\begin{tabular}{|c|c|c|c|c|c|c|}
\hline & & $10 \%$ & $1.157 \mathrm{E}-02$ & $2.459 \mathrm{E}-04$ & $2.094 \mathrm{E}-07$ & 0.974 \\
\hline & & $1 \%$ & $8.104 \mathrm{E}-03$ & $-6.646 \mathrm{E}-04$ & $1.021 \mathrm{E}-06$ & 0.936 \\
\hline & 0 & $5 \%$ & $6.187 \mathrm{E}-03$ & $-7.388 \mathrm{E}-04$ & $1.185 \mathrm{E}-06$ & 0.921 \\
\hline & & $10 \%$ & $3.381 \mathrm{E}-03$ & $-3.187 \mathrm{E}-04$ & $6.935 \mathrm{E}-07$ & 0.892 \\
\hline & & $1 \%$ & $-1.220 \mathrm{E}-03$ & $-4.227 \mathrm{E}-04$ & $6.665 \mathrm{E}-07$ & 0.996 \\
\hline \multirow[t]{5}{*}{$\begin{array}{l}\text { Wet-dry } \\
\text { cycle }\end{array}$} & $15 \%$ & $5 \%$ & $-4.093 \mathrm{E}-03$ & $-4.637 \mathrm{E}-05$ & 4.813E-07 & 0.992 \\
\hline & & $10 \%$ & $3.517 \mathrm{E}-04$ & $3.177 \mathrm{E}-04$ & $5.314 \mathrm{E}-07$ & 0.999 \\
\hline & & $1 \%$ & $5.891 \mathrm{E}-03$ & 2.833E-04 & 4.234E-08 & 0.987 \\
\hline & $30 \%$ & $5 \%$ & $5.360 \mathrm{E}-03$ & $3.587 \mathrm{E}-04$ & $4.675 \mathrm{E}-07$ & 0.994 \\
\hline & & $10 \%$ & 1.078E-02 & 6.404E-04 & $2.301 \mathrm{E}-07$ & 0.990 \\
\hline
\end{tabular}

In the equation (1), $t$ is the sulfate corrosion age; $a, b$, $c$ represents the trial-related coefficient respectively.Based on the test data, researchers conducted regression fitting and finally got the fitting coefficients in the equation (1), as shown in table 2 .

From figure 6 to figure 9 , the evolutionary relationship of the damage rate with corrosion age of concrete is shown.

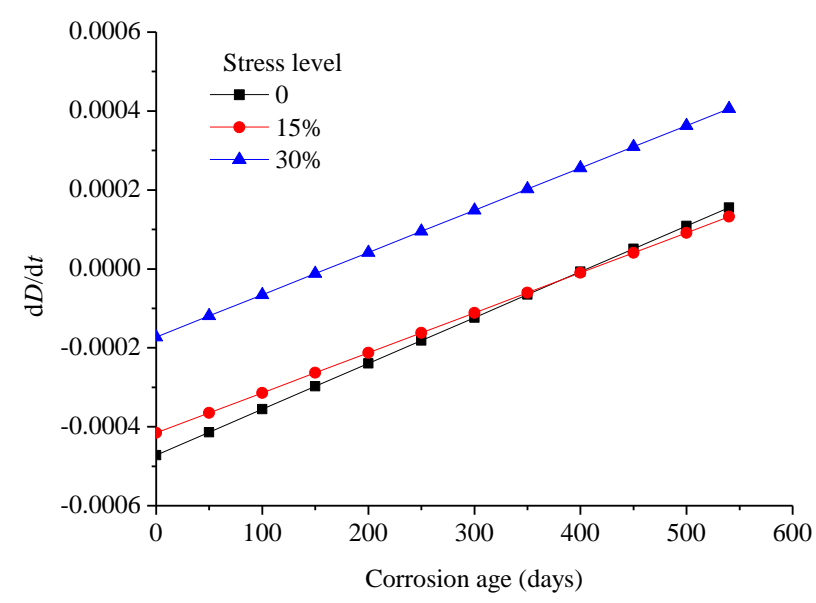

Figure 6. Evolution of concrete damage rate under different stress levels (LM-C1)

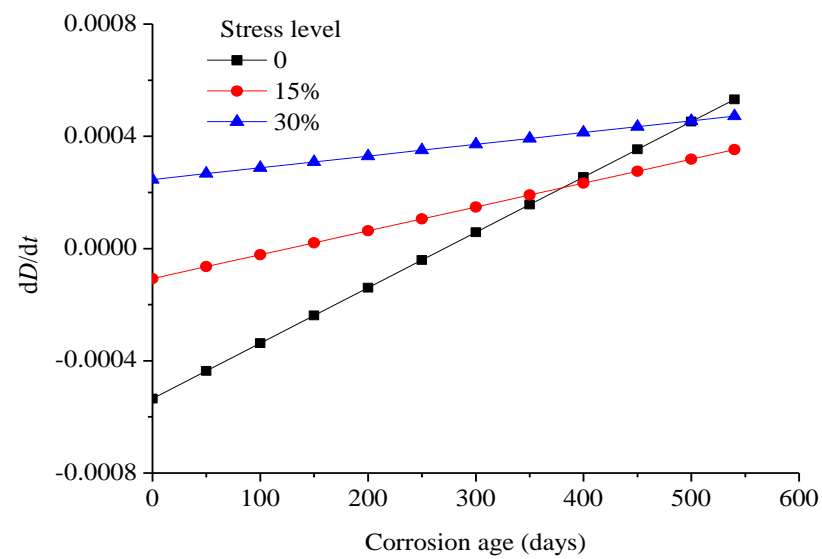

Figure 7. Evolution of concrete damage rate under different stress levels (LM-C10)

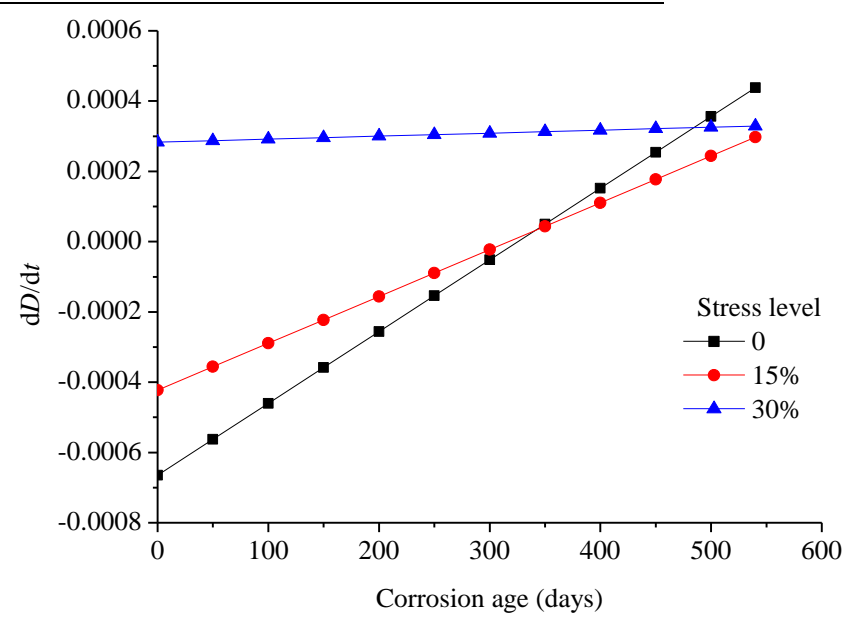

Figure 8. Evolution of concrete damage rate under different stress levels (DW-C1)

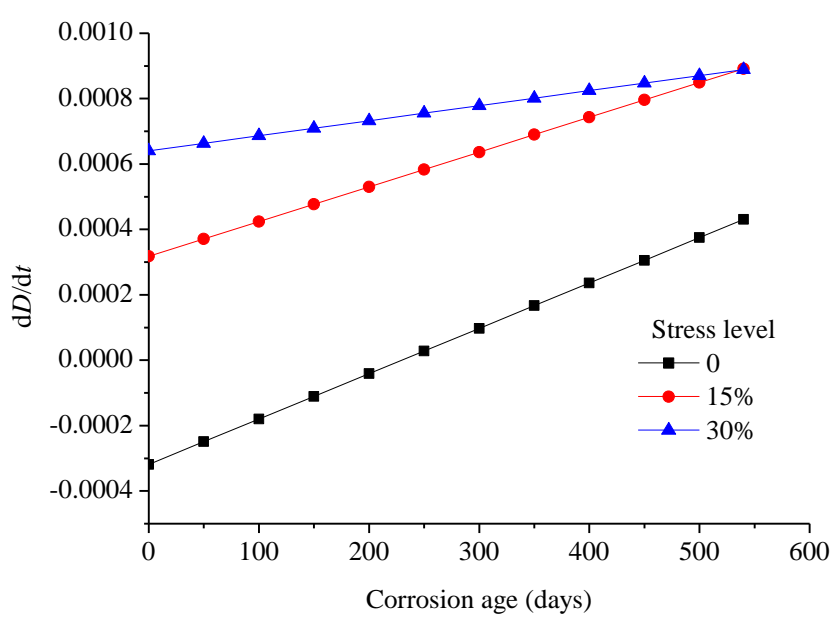

Figure 9. Evolution of concrete damage rate under different stress levels (DW-C10)

From figure 6 and figure 7, we can know that in the environment of long-term immersion, when the concentration of corrosion solution concentration is $1 \%$, the concrete damage rate increases with the stress level's increasing but the incremental damage rate has no significant change with the improvement of stress level. The increment of concrete damage rate increases more 
and more slowly with the stress level when the concentration of corrosion solution is $10 \%$. From figure 8 and figure 9 , in the environment of wet and dry cycles and when the corrosion solution concentration is $1 \%$, the concrete damage rate increment increases more and more slowly with the stress level. Before corrosion age reaches 350 days, the concrete damage rate increases with corrosion age and after 350 days, the concrete damage rate has the trend of first increasing and then decreasing with corrosion age. When the concentration of corrosion solution is $10 \%$, the concrete damage rate increases with corrosion age but the incremental damage rate decreases with the improvement of stress level.

\section{Conclusions}

In this paper, the test researches were carried out on the concrete mass and dynamic elastic modulus under the effects of sustained loading, sulfate attack and dry-wet circulation, and the test phenomenon and results were discussed and analyzed, and the durability damage model of the concrete under the effects of sustained loading, sulfate attack and dry-wet circulation was proposed, then the rationality of the model was discussed.

\section{Acknowledgments}

This study was funded by the Jiangxi Province Natural Sciences Fund Projects of China [grant number 20161BAB206120].

\section{References}

1. Neville A. Consideration of durability of concrete structures: past, present, and future [J]. Mater. Struct., 2001, 34(2): 114-118.

2. Tixier R, and Mobasher. Modeling of damage in cement-based materials subjected to external sulfate attack. I: formulation [J]. J. Mater. Civ. Eng., 2003, 15(4): 305-313.
3. Tixier R, and Mobasher. Modeling of damage in cement-based materials subjected to external sulfate attack. II: comparison [J]. J. Mater. Civ. Eng., 2003, 15(4): 314-322.

4. Saetta A. Mechanical behavior of concrete under physical-chemical attacks [J]. J. Eng .Mech-ASCE, 1998, 124(10): 1100-1109.

5. Saetta A V, Scotta R, and Vitaliani R. Coupled environmental-mechanical damage model of $\mathrm{RC}$ structures [J]. J. Eng .Mech-ASCE, 1999, 125(8): 930-940.

6. Saetta A. Deterioration of reinforced concrete structures due to chemical-physical phenomena model-based simulation [J]. J. Mater. Civ. Eng., 2005, 17(3): 313-319.

7. Kuhl D, Bangert F, and Meschke G. Coupled chemo-mechanical deterioration of cementitious materials. Part I: Modeling [J]. Int. J. Solids Struct., 2004, 41(1): 15-40.

8. Kuhl D, Bangert F, and Meschke G. Coupled chemo-mechanical deterioration of cementitious materials. Part II: Numerical methods and simulations [J]. Int. J. Solids Struct., 2004, 41(1): 41-67.

9. Schneider U, and Chen S W. Modeling and empirical formulas for chemical corrosion and stress corrosion of cementitious materials [J]. Mater. Struct., 1998, 31(10): 662-668.

10. Maes M A, Wei X, and Dilger W H. Fatigue reliability of deteriorating prestressed concrete bridges due to stress corrosion cracking $[\mathrm{J}]$. Can.J. Civi. Eng., 2001, 28(4): 673-683.

11. Xi Y P, and Ababneh A. The coupling effects of environmental and mechanical loadings on durability of concrete [C]. Proc. Int. Conf. Adv. Concr. Struct., Xuzhou, China, 2003: 354-365.

12. Minstry of Housing and Urban-Rural Development of the People's Republic of China. Standard for test methods of long-term performance and durability of ordinary concrete [S]. GB/T 50082-2009. Beijing: China Architecture \& Building Press, 2009. 